\title{
FACTORS IMPACTING ON PATIENT COMPLIANCE WITH MEDICAL ADVICE: EMPIRICAL STUDY
}

\author{
Katarzyna Krot, JoÃo Pedro Sousa
}

\begin{abstract}
A B STR A C T
The purpose of this paper to identify factors which have a bearing on compliance with medical advice in various age groups. The survey was conducted, using the CAWI method, on a representative sample of 1000 respondents who declared having used healthcare services in the previous six months. Control of competences is one of the strongest factors which is common for the oldest and youngest groups. Interestingly, trust in the integrity and honesty of doctors is significant for the youngest patients, i.e., the higher is the level of trust, the lower is the tendency to non-comply. Another type of trust is related to the benevolence of doctors and is significant to patients of the middle age group. Satisfaction is a significant predictor in the two oldest groups of patients. High levels of satisfaction seem to deter people from non-adherence to recommended treatment regimens. The results of the present study provide knowledge about the nature and diversity of factors behind patient compliance in various age groups.
\end{abstract}

KEY WORDS

compliance with medical advice, doctor-patient relationship, trust, satisfaction

DOI: 10.1515/emj-2017-0016
Corresponding author:

Katarzyna Krot

Białystok University of Technology Management Department, Poland e-mail: k.krot@pb.edu.pl

João Pedro Sousa

Inst. Sup. Entre Vouga e Douro Unidade de Investigação e Internacionalização - Marketing Department, Portugal e-mail: j.sousa@doc.isvouga.pt

\section{INTRODUCTION}

The increase in the degree patient compliance with medical recommendations brings considerable clinical and economic benefits for both patients and entire healthcare systems. However, it is not an easy goal to achieve because of numerous factors that can influence the behaviour of patients. To encourage people to be compliant, service providers must iden- tify the determinants of compliance with medical recommendations and understand what barriers may discourage patients from desirable behaviour patterns (Krueger et al., 2005; Golin et al., 2002). Numerous studies devoted to this issue concern patient factors, i.e. social and demographic characteristics of patients (Golin et al., 1996), economic and environmental determinants, and the significance of the type 
of illness (Catz et al., 2000). Considerable attention has also been paid to the influence the age of patients has on compliance, although such analyses usually concern selected medical conditions (Hinkin et. al., 2004; Michetti et. al., 2016; Krueger et. al., 2015). Research results indicate that with age patients become more obedient and scrupulously follow medical recommendations. However, such conclusions seem unsatisfactory when one considers the multidimensional consequences of failure to adhere to medical regimens. Therefore, this paper aims to identify factors that have a bearing on compliance with medical advice in various age groups based on results of representative surveys.

\section{FACTORS DETERMINING COMPLI- ANCE WITH MEDICAL ADVICE}

Compliance with medical advice is understood as the degree to which a patient's behaviour associated with taking medication, adherence to recommended diet, or other changes in lifestyle are consistent with the advice of their physician. This definition implies that the medical recommendations are correct and beneficial for the patient and that the patient's rational behaviour should mean following that advice (Roberson, 1992).

As research results suggest, patient compliance depends on a number of factors, which have been grouped into several categories: patient factors (Golin et al., 1996; Murphy et al., 2000; Roberts, 2000), characteristics (complexity) of treatment schedule (Cramer et al., 1989; Turner et al., 2000; Ostrop et al., 2000), nature of the doctor-patient relationship (Anderson, 1990; Rost, 1989; Kaplan et al., 1989), type of disease, social and environmental factors (Catz et al., 2000; Gordillo et al., 1999). Sometimes, the outcomes of research are ambivalent due to relatively low values of correlation coefficients (Vermeire et al., 2001). However, it has been indicated that older age, a higher level of education, higher socio-economic status, as well as being retired and married, are associated with better compliance with treatment (Thomas et al., 2006). Other positive factors include an accessible and comprehensible form of communicating medical information, continuity of healthcare, patient satisfaction, shorter intervals between appointments, and shorter waiting time (Thomas et al., 2006; Griffth, 1990).
Meanwhile, the complexity of advice regarding therapy methods and insufficient communication between doctors and patients are mentioned as the main reasons for non-compliance with treatment, particularly among older patients with memory impairment (Donovan, 1995).

Other potential ways to enhance the degree of patient compliance include the types of prescribed medications and techniques to encourage patients to take right doses. And yet, research results unequivocally disprove the efficiency of such practices. Simplification of drug treatment schemes, prescribing fewer medications to be taken at a given time, and development of longer-acting medicines result in simplified treatment regimens rather than in better adherence indicators (Vermeire et al., 2001).

It is the relationship that is established between a patient and a doctor that determines whether the former will comply with the latter's recommendations. However, the nature of this relationship is rather difficult to examine (Vermeire et al., 2001). This is particularly true as regards the duration and frequency of appointments and the quality of this relationship: attitudes of a physician towards patients, their respect for patient concerns, their empathy, and the manner of conveying information (DiMatteo, 1994). This last factor has been investigated in more detail. It turns out that a clear explanation of the correlation between treatment and disease increases the likelihood of good compliance with doctor's recommendations. On the other hand, describing the effects of therapy can adversely affect patient behaviour. Meanwhile, an educational approach aimed at helping patients understand treatment guidelines leads to better adherence to medical advice (Donovan, 1995).

Therefore, from the point of view of a patient, interpersonal skills of doctors are one of the key factors taken into account when assessing the performance of physicians (Anderson \& Dedrick, 1990; Mead \& Bower, 2000; Mercer et al., 2001; Assem \& Dulewicz, 2014). Among these skills, one should mention the ability to inspire patient trust (Mechanic \& Meyer, 2000; Hall et al., 2001; Maynard \& Bloor, 2003; da Silva Terres et al., 2015). The character of the doctor-patient relationship is a crucial factor that enables the achievement of the desired health outcomes. Medical services belong to the category of high-consequence exchanges, i.e. are associated with difficult choices which might induce stress and strong emotional reactions (Botti et al., 2009; da Silva Terres et al., 2015). This explains why trust is so tremen- 
dously significant for healthcare services. Dugan et al. (2005) define it as the patient acceptance of dependence and belief that the doctor will ensure the provision of medical service with the patient's interest in mind (Hall et al., 2001; Gilson, 2003).

Lack of trust can contribute to patient dissatisfaction and a sense of threat to one's health (Zineldin, 2015). Nowadays, patients are increasingly better informed and more willing to participate in decisions regarding their health. As a result, the interdependence of doctors and patients is stronger, which means that trust is more dependent on communication, information conveyed during appointments and other factors which strengthen the reliability of doctors' actions (Rowe \& Calnan, 2006; Assem \& Dulewicz, 2014). The shiftin thenature of the doctor-patient relationship from paternalism to partnership may significantly influence the attitude of patients towards health-related issues, including compliance to treatment. Decisions regarding the course of therapy are taken jointly after the patient has been appropriately informed of any relevant facts that enable him or her to take such decisions (Vermeire et al., 2001). Patient participation in the care-related decision-making is associated with positive outcomes, such as enhanced adherence, improved illness-related knowledge and health behaviour (Castroa et al., 2016; Bertakis \& Azari, 2011). This type of involvement seems to be the optimal option both for the patients and doctors (Szymańska, 2016).

The results of a study by Thom (2001) emphasise the significance and impact of the trust in doctors on patient behaviour. According to the author, higher levels of trust ensure a greater likelihood of appropriate absorption of medical information as well as compliance to new drug regimens and acceptance of treatment methods and diagnostics. Krawczyńska (2013) points out that trust in physicians helps create positive patient attitudes to medical innovations and the degree in which they are used in therapy (despite information about the low efficacy of new medical procedures). Erosion of trust leads to other negative consequences, e.g. doubt in medical advice, selfmedication or modification of medical recommendations (Krot \& Rudawska, 2016).

Moreover, research results indicate that distrust affects adherence by increasing treatment-related psychological distress and weakening treatment benefit beliefs (Thrasher et al., 2008). Distrust stemming from overgeneralisation is a neutral or even hostile attitude towards other unfamiliar members of society. The definition holds that distrust is expressed by such behaviours as guardedness, control (bureaucratic and legal), monitoring, and alertness. Finally, distrust is reflected in social restrictions, i.e. withdrawal from social bonds or business contacts, reluctance to cooperate or share resources (Lewicki \& Mcallister, 1998). Generalised distrust results in an unwillingness to co-operate, which, in turn, weakens the social efficiency of the system.

Patient satisfaction is undoubtedly another factor behind the degree of patient compliance. Satisfaction has a strong impact on the health-related behaviours of patients. Study results show that contented patients are more conscientious when it comes to complying with their doctors' advice (McKinley et al., 1997) and follow the recommendations they have received (Grogan et al., 2000; Dang et al., 2013).

Meanwhile, dissatisfied patients change doctors more frequently, which not only disrupts the treatment process but is also costly for patients themselves as well as for the entire healthcare system (Baker, 1990; Andaleeb, 2001). Besides, satisfaction with a medical appointment is a vital aspect that influences further health-related decisions. Satisfied patients return to their doctors more often should such a need arise (Ramsaran-Fowdar, 2005).

\section{AgE OF PATIENTS AND COMPLI- ANCE WITH MEDICAL ADVICE}

The results of numerous studies clearly indicate that age is a strong predictor of one's beliefs about therapy effectiveness and adherence (Reynolds et al., 2004). Older age tends to be associated with significantly better medication adherence (Hinkin et al., 2004; Michetti et al., 2016; Krueger et al., 2015). The higher adherence amongst older patients might be due to their unwillingness to take risks related to their health (Michetti et al., 2016). Other authors point out that taking medication possibly requires less alteration in lifestyle for older people or these lifestyle alterations necessary for successful adherence are less burdensome for older individuals, who may be able to easier accommodate pill-taking into their daily lives. Older individuals are more likely to have prior experience taking medication for other age-related illnesses and, therefore, may already have become more accustomed to such a routine (Barclay et al., 2007). 
Besides, older patients might have a greater awareness of mortality and thus have a stronger motivation to adhere to the advice of their physicians. Scrupulous compliance with medical instructions might partly contribute to the lengthening of these patients' lives, as well as explain the statistically significant difference between older and younger patients (Barclay et al., 2007).

The results of multivariate analyses prove that among younger patients, perceived treatment utility and heightened feelings of self-efficacy are both predictive of adherence. Younger patients believe in their own capabilities and must trust in the recommended treatment methods to follow medical recommendations. The outcomes of surveys among older patients are vastly different. It turns out that neither of the above variables influenced patient adherence to the recommendations of their doctors (Barclay et al., 2007).

\section{RESEARCH METHODS}

The studies conducted so far demonstrate that compliance with medical advice is strictly dependent on several determinants, both patient-related, including the demographic factors (Murphy et al., 2000; Roberts, 2000), and those related to the course of the therapeutic process (Ostrop et al., 2000; da Silva Terres et al., 2015). Despite some difficulty in identification of such a set of factors, age is definitely a variable to be taken into account (Krueger et al., 2015; Krivoy et al., 2015). Additionally, it seems that factors which impact patient behaviour can vary depending on the age of an individual, although little research has been devoted to this issue (Barclay et al., 2007). Therefore, the purpose of the present study is to attempt identifying the factors which determine compliance with medical advice in different age groups.

The statements used in the questionnaire, which measure each variable (trust, distrust, satisfaction, and medical compliance) have been developed based on literature study (Tab. 1). Each statement was presented to respondents with a five-degree Likert scale. The scales gauging the variables were verified by means of a factor analysis.

The survey was conducted in years 2015/2016, using the CAWI method, on a representative sample of 1000 respondents who declared having used healthcare services in the previous six months. Tab. 2 sums up the characteristics of the research sample.

\section{RESEARCH RESULTS}

Compliance with medical recommendations was analysed by means of statements on taking medications, following the schedules designed by doctors or recommended changes in lifestyle (on a five-point Likert scale from 'definitely agree' to 'definitely disagree'). Respondents declared they tended to adhere to medical advice, although some of them admitted that complying with treatment regimens could be troublesome. The greatest difficulties in following recommendations were related to changes in lifestyle, i.e. altering a diet or levels of physical activity (arithmetic mean 2.85). Moreover, patients occasionally forgot to

Tab. 1. Bibliographical references

\begin{tabular}{|l|l|}
\hline \multicolumn{1}{|c|}{ VARIABLE } & \multicolumn{1}{c|}{ BIBLIOGRAFICAL REFERENCES } \\
\hline Trust in doctor's competences & Anderson \& Dedrick, 1990; Dugan, Hall \& Trachtenberg, 2005 \\
\hline Control of doctor's competences & Anderson \& Dedrick, 1990; Dugan, Hall \& Trachtenberg, 2005 \\
\hline Trust in benevolence and emotional support & Anderson \& Dedrick, 1990; Dugan, Hall \& Trachtenberg, 2005 \\
\hline Belief that doctors act in the interest of patients & Anderson \& Dedrick, 1990; Dugan, Hall \& Trachtenberg, 2005 \\
\hline Trust in the quality of communication & Anderson \& Dedrick, 1990; Dugan, Hall \& Trachtenberg, 2005 \\
\hline Trust in the integrity and honesty of doctors & Anderson \& Dedrick, 1990; Dugan, Hall \& Trachtenberg, 2005 \\
\hline $\begin{array}{l}\text { Adherence to Refills and Medications scale - ARMS - 13 } \\
\text { statements }\end{array}$ & Kripalani et al., 2009 \\
\hline Distrust resulting from overgeneralisations & Skarżyńska, 2012 \\
\hline Patient satisfaction & $\begin{array}{l}\text { Elleuch, 2008; Schee, Groenewegen \& Friele, 2006; Trumble, } \\
\text { O'Brien, O'Brien \& Hartwig, 2006; van der Schee, Groenewegen } \\
\text { \& Friele, 2006 }\end{array}$ \\
\hline
\end{tabular}

Source: authors' work based on literature review. 
Tab. 2. Structure of research sample

\begin{tabular}{|c|c|c|c|c|c|}
\hline \multicolumn{3}{|c|}{ INCOME } & \multicolumn{3}{|c|}{ GENDER } \\
\hline & NUMBER & PERCENT & & NUMBER & PERCENT \\
\hline Up to PLN 1000 & 79 & 7.9 & woman & 600 & 60.0 \\
\hline PLN 1001 to PLN 1400 & 91 & 9.1 & man & 400 & 40.0 \\
\hline PLN 1401 to PLN 1800 & 108 & 10.8 & \multicolumn{3}{|c|}{ AGE } \\
\hline PLN 1801 to PLN 2000 & 110 & 11.0 & $18-24$ & 76 & 7.6 \\
\hline PLN 2001 to PLN 2500 & 74 & 7.4 & $25-34$ & 176 & 17.6 \\
\hline PLN 2501 to PLN 3000 & 122 & 12.2 & $35-44$ & 175 & 17.5 \\
\hline PLN 3001 to PLN 5000 & 158 & 15.8 & $45-59$ & 287 & 28.7 \\
\hline Over PLN 5000 & 126 & 12.6 & \multirow{2}{*}{ Over 60} & \multirow{2}{*}{286} & \multirow{2}{*}{28.6} \\
\hline Difficult to say & 44 & 4.4 & & & \\
\hline \multicolumn{3}{|c|}{ PLACE OF RESIDENCE } & \multicolumn{3}{|c|}{ LEVEL OF EDUCATION } \\
\hline Village & 335 & 33.5 & primary & 66 & 6.6 \\
\hline Town up to 100,000 residents & 340 & 34.0 & vocational & 182 & 18.2 \\
\hline Town 100,000 - 499,000 residents & 183 & 18.3 & secondary & 383 & 38.3 \\
\hline Town over 500,000 residents & 142 & 14.2 & university & 369 & 36.9 \\
\hline
\end{tabular}

Source: authors' work based on survey results.

take prescribed drugs (arithmetic mean 2.35), failed to fill a prescription (arithmetic mean 2.35), failed to take medication (arithmetic mean 2.37), or even discontinued treatment of their own accord (arithmetic mean 2.30).

Because the respondents were asked about a variety of behaviours relating to compliance with medical advice, the conducted factor analysis aimed at classifying that wide array of behaviours into relatively uniform subcategories. The factor analysis was performed with the varimax method. Each factor was given a category based on the value of factor loadings. For each identified category, statistical rigour was verified, which proved to be satisfactory as Cronbach's alfa equalled 0.64 .

A category labelled 'patient disobedience' was identified among the studied behaviours, and meant an inclination to change drug dosage independently (Q6), stop taking medication altogether (Q7), or even abandon treatment (Q9) as well as refuse to comply with recommendations regarding lifestyle changes (Q12). This category also comprises failure to fill a prescription (Q3).

As previous research results indicate, there are several factors that impact the degree, to which medical recommendations are respected. Because of this, before analysing the outcomes of the discussed survey, it was assumed that 'patient disobedience' could be affected by: all the dimensions of trust in physi-
Tab. 3. Results of the factor analysis

\begin{tabular}{|l|r|}
\hline \multicolumn{1}{|c|}{ VARIABLES } & FACTOR - DISOBEDIENCE \\
\hline Q_3 & 0.61 \\
\hline Q_6 & 0.54 \\
\hline Q_7 & 0.76 \\
\hline Q_9 & 0.70 \\
\hline Q_12 & 0.42 \\
\hline
\end{tabular}

Source: authors' work based on survey results.

cians, generalised distrust, satisfaction, and demographic variables gender and education.

Patient confidence in their physicians, analysed by means of a five-point Likert scale, consisted of four dimensions confirmed by a factor analysis (varimax method). Each factor was given a category based on the value of factor loadings. Apart from trust in the competences of doctors, the conducted analysis allowed the author to identify four additional dimensions: control of competences, trust in benevolence and emotional support for patients, belief that doctors acted in the best interest of their patients, trust in the quality of communication, and trust in the integrity and honesty of doctors.

Like trust, distrust resulting from overgeneralisation was measured using a five-point Likert scale. Using a factor analysis, two dimensions were identified: relational distrust (Cronbach's alfa: 0.25) and distrust of strangers (Cronbach's alpha: 0.55). 
Tab. 4. Factors influencing adherence to medical advice among respondents up to 34 years of age: the regression model

\begin{tabular}{|c|c|c|c|c|c|c|}
\hline VARIABLE & $\mathrm{B}^{*}$ & ST. ERROR OF B* & B & ST. ERROR OF B & $T(232)$ & $\mathbf{P}$ \\
\hline Constant & & & 11.40 & 2.16 & 5.27 & 0.00 \\
\hline Control of competences & 0.25 & 0.06 & 0.35 & 0.09 & 4.09 & 0.00 \\
\hline Trust in integrity and honesty & -0.23 & 0.09 & -0.24 & 0.09 & -2.65 & 0.01 \\
\hline Gender & -0.12 & 0.06 & -0.99 & 0.47 & -2.10 & 0.04 \\
\hline Relational distrust & 0.13 & 0.06 & 0.18 & 0.08 & 2.15 & 0.03 \\
\hline
\end{tabular}

Source: authors' work based on survey results.

Tab. 5. Factors influencing adherence to medical advice among respondents aged 35-44 years: the regression model

\begin{tabular}{|c|c|c|c|c|c|c|}
\hline VARIABLE & $\mathrm{B}^{*}$ & ST. ERROR OF B* & B & ST. ERROR OF B & $\mathrm{T}(147)$ & $\mathbf{P}$ \\
\hline Constant & & & 14.41 & 3.01 & 4.77 & 0.00 \\
\hline Satisfaction & -0.30 & 0.09 & -0.19 & 0.06 & -3.17 & 0.00 \\
\hline Distrust of strangers & 0.19 & 0.08 & 0.33 & 0.14 & -2.34 & 0.02 \\
\hline $\begin{array}{l}\text { Trust in benevolence and } \\
\text { emotional support }\end{array}$ & -0.19 & 0.09 & -0.20 & 0.09 & 2.08 & 0.04 \\
\hline
\end{tabular}

Source: author's work based on survey results.

Satisfaction is a one-dimensional construct and was gauged using eight statements in a five-point Likert scale format (Cronbach's alpha: 0.85).

Bearing in mind the purpose of this paper, i.e. identification of factors determining patient compliance in particular age groups, a multiple regression analysis was performed, using the method of stepwise regression, where the tendency to disobey medical advice was the dependent variable, while the abovementioned determinants were independent variables, and the age of the respondents (divided into three categories: up to 34 years of age, 35-44 years and above, and over 45) was the grouping variable. As a result, three models containing statistically significant factors influencing patient compliance were obtained.

Three main dimensions of trust have a crucial impact on adherence to medical advice by the youngest respondents (up to 34 years of age): control of competences (positive correlation) and trust in the integrity and honesty of doctors (negative correlation), as well as relational distrust (negative correlation) and gender (Tab. 4). Among the youngest patients, control of competences is the strongest determinant of disobedience, i.e. the more a patient is inclined to verify the diagnoses provided by doctors, the more often one becomes insubordinate, changing treatment regimens of one's own accord. At the same time, the greater the declared distrust in relationships with others, the more proclivity to disobedience. Meanwhile, confidence in the integrity and honesty of doctors is a factor that prevents respondents from disobeying their medical recommendations. It is worth mentioning that among the youngest patients, it is men who are more likely to ignore medical advice.

In the second age group, i.e. people aged 35-44 years (Tab. 5), factors determining compliance with medical advice turned out to be slightly different. For these respondents, patient satisfaction as well as trust in the benevolence of doctors and emotional support proved to be statistically significant factors that influenced their adherence to medical recommendations. Moreover, their compliance was largely affected by their distrust of strangers: the higher it was, the greater was the 'independence' of patients.

As far as the oldest age group is concerned, patient compliance is determined firstly by control of competences (positive correlation), patient satisfaction (negative correlation), and the gender of the survey participants (Tab. 6). The greater is the need to control the diagnoses made by doctors, the higher is the likelihood that the patients will arbitrarily change treatment regimen. On the other hand, as the satisfaction of patients grows, their tendency to defy medical advice diminishes. Gender is a factor that determines patient compliance to slightly a lesser extent. Women show less inclination to disobey. 
Tab. 6. Factors influencing adherence to medical advice among respondents over 45 years of age: the regression model

\begin{tabular}{|l|r|r|r|r|r|r|}
\hline \multicolumn{1}{|c|}{ VARIABLE } & \multicolumn{1}{c|}{ B $^{*}$} & \multicolumn{1}{c|}{ ST. ERROR OF B* } & \multicolumn{1}{c|}{ B } & \multicolumn{1}{c|}{ ST. ERROR OF B } & \multicolumn{1}{c|}{ T(474) } & P \\
\hline Constant & & & 11.87 & 1.45 & 8.17 & 0.00 \\
\hline Control of competences & 0.18 & 0.04 & 0.28 & 0.07 & 3.92 & 0.00 \\
\hline Satisfaction & -0.14 & 0.06 & -0.10 & 0.04 & -2.50 & -1.80 \\
\hline Gender & -0.08 & 0.04 & -0.71 & 0.39 & & 0.01 \\
\hline$R^{\wedge} 2=0.05 F(4.474)=6.67 p<0.00$ std. error of estimation: 4.18 \\
\hline
\end{tabular}

Source: authors' work based on survey results.

In the last model, the $\mathrm{r} 2$ indicator amounts to $5 \%$, which might mean that only 5 percent of the variability of the dependent variable patient compliance is explained by the independent variables, i.e. those included in the model. In the social sciences, where it is hard to specify such models, low R-square values are often expected. Consequently, researchers recommend considering such models be provided that the independent variables are statistically significant because only then their predictive value is confirmed. Possible doubts arise as to the precision of explanation, although in social sciences, this is less important (Bedeian \& Mossholder, 1994).

\section{CONCLUSIONS}

Improving the degree, to which patients adhere to their medical advice has a great significance for the state of their health as well as the condition of the entire healthcare system. For this reason, numerous researchers have devoted their studies to this problem (Cramer et al., 1989; Vermeire et al., 2001; Golin et al., 2002). Interest in this research area is motivated not only by concern for the potential consequences of non-compliance with medical regimens but also stems from the variety of reasons for the 'insubordination' of patients. If we specify what these reasons are, it will be possible to prevent undesirable behaviours.

The age of a patient is a factor that determines the consistency of adherence to medical recommendations (Hinkin et al., 2004; Michetti et al., 2016; Krueger et al., 2015). This explains why attempts have been made to identify the factors that influence the level of patient disobedience in three age groups. As the results of previous research indicate, the reasons for willingness to comply can be found in the quality of the doctor-patient relationship, i.e., among other things, trust in the doctor (Thom, 2001), satisfaction with the medical appointment (McKinley et al., 1997; Grogan et al., 2000; Dang et al., 2013), and the overall distrust towards strangers (Thrasher et al., 2008).

Control of competences is one of the strongest factors which is common for the oldest and youngest groups. In both of these age groups, constant verification of doctors' decisions leads to a greater freedom of interpreting medical advice and introducing arbitrary changes to medical regimens, i.e. alterations in treatment methods, drug dosages, or even discontinuation of prescribed medications. Interestingly, trust in the integrity and honesty of doctors is significant for the youngest patients, i.e., the higher is the level of trust, the lower is the tendency to non-comply. Meanwhile, among older patients, this kind of trust is not important at all. Another type of trust is related to the benevolence of doctors and is significant to patients of the middle age group. Satisfaction is a significant predictor in the two oldest groups of patients. High levels of satisfaction seem to deter people from non-adherence to recommended treatment regimens.

The behaviour of patients, particularly younger ones, is also dependent on the level of distrust. However, in the youngest age group, relational distrust plays the most important role, while in the age group 35-44, distrust of strangers is more significant.

Having analysed the determinants of patient behaviour, one can conclude that the compliance of the youngest patients depends on the relational approach, i.e. the ability to build trust-based relationships with more or less familiar doctors or other strangers, to a greater extent than in the other age groups. In the age group 35-44, patients are more responsive to 'enjoyment', i.e. their level of obedience depends on a satisfying and congenial atmosphere. Meanwhile, the behaviour of the oldest patients is solely dependent on the character of their relationship with a doctor. 
The results of the present study confirm that age is a strong determinant of patients' adherence to medical advice. Additionally, they provide knowledge about the nature and diversity of factors that lie behind patient compliance in various age groups. This knowledge can prove particularly useful to doctors as it offers guidelines for creating such relationships with patients that will encourage and motivate them to follow the recommendations of their physicians.

\section{ACKNOWLEDGEMENTS}

The study has been conducted as part of the project S/WZ/2/2017 and financed by the Ministry of Science and Higher Education (MNiSW).

\section{LITERATURE}

Anderson, L. (1989). Health care communication and selected psychological adherence in diabetes management. Diabetes Care, 13, 66-77.

Anderson, L. A., \& Dedrick, R. F. (1990). Development of the trust in physician scale: a measure to assess interpersonal trust in patient-physician relationships. Psychological Reports, 67(3), 1091-1100.

Assem, B. V. D., \& Dulewicz, V. (2014). Patient satisfaction and GP trustworthiness, practice orientation and performance. Journal of Health Organization and Management, 28(4), 532-547.

Barclay, T. R., Hinkin, Ch. H., Castellon, S. A., Mason, K. I., Reinhard, M. J., Marion, S. D., Levine, A. J., \& Durvasula, R. S. (2007). Age-associated predictors of medication adherence in HIV-positive adults. Health beliefs, self-efficacy, and neurocognitive status. Health Psychology, 26(1), 40-49.

Bedeian, A. G., \& Mossholder, K. W. (1994). Simple question, not so simple answer: Interpreting interaction terms in moderated multiple regression. Journal of Management, 20(1), 159-165.

Bertakis, K. D., \& Azari, R. (2011). Patient-centered care is associated with decreased health care utilization. Journal of the American Board of Family Medicine, 24, 229-239.

Botti, S., Orfali, K., \& Iyengar, S. S. (2009). Tragic choices: autonomy and emotional responses to medical decisions. Journal of Consumer Research, 36(3), 337-352.

Castroa, E. M., Van Regenmortelb, T., Vanhaechtd, K., Sermeusd, W., \& Van Heckef, A. (2016). Patient empowerment, patient participation and patient-centeredness in hospital care: A concept analysis based on a literature review. Patient Education and Counseling, 99(12), 1923-1939. doi: 10.1016/j.pec.2016.07.026
Catz, S., Kelly, J., Bogart, L., Benotsch, E., \& McAuliffe, T. (2000). Patterns, correlates, and barriers to medication adherence among persons prescribed new treatments for HIV disease. Health Psychology, 19(2), 124-133.

Cramer, J., Mattson, R. H., Prevey, M. L., Scheer, R. D., \& Ouellette, V. (1986). How often is medication taken as prescribed? A novel assessment technique. JAMA, 261(22), 3272-3277.

da Silva, M., Pizzutti dos Santos, T. C., \& Basso, K. (2015). Antecedents of the client's trust in low- versus highconsequence decisions. Journal of Services Marketing, 29(1), 26-37.

DiMatteo, M. R. (1994). Enhancing patient adherence to medical recommendations. JAMA, 271(1), 79-83.

Donovan, J. L. (1995). Patient decision making. The missing ingredient in compliance research. International Journal of Technological Assessment in Health Care, 11(3), 443-455.

Dugan, E., Trachtenberg, F., \& Hall, M. A. (2005). Development of abbreviated measures to assess patient trust in a physician, a health insurer, and the medical profession. BMC Health Services Research, 64(5), 1-7.

Elleuch A. (2008). Patient satisfaction in Japan. International Journal of Health Care Quality Assurance, 21(7), 692-705.

Gilson, L. (2003). Trust and the development of health care as a social institution. Social Science \& Medicine, 56(7), 1453-1568.

Golin, C. E., DiMatteo, M. R., \& Gelberg, L. (1996). The role of patient participation in the doctor visit. Implications for adherence to diabetes care. Diabetes Care, 19(10), 1153-1164

Golin, C. E., Liu, H., Hays, R. D., Miller, L. G., Beck, C. K., Ickovics, J., Kaplan, A. H., \& Wenger, N. S. (2002). A prospective Study of Predictors of Adherence to Combination Antiretroviral Medication. Journal of General Internal Medicine, 17(10), 756-765.

Gonzalez, J. S., Penedo, F. J., Llabre, M. M., Durán, R. E., Antoni, M. H., Schneiderman, N., \& Horne, R. (2007). Physical symptoms, beliefs about medications, negative mood, and long-term HIV medication adherence. Annals of Behavioral Medicine, 34(1), 46-55.

Gordillo, V., Del Amo, J., Soriano, V., \& Gonzalez-Lahoz, J. (1999). Sociodemographic and psychological variables influencing adherence to antiretroviral therapy. AIDS, 13(13), 1763-1769.

Griffth, S. (1990). A review of the factors associated with compliance and the taking of prescribed medicines. British Journal of General Practice, 40(332), 114-116.

Hall, M. A., Dugan, E., Zheng, B., \& Mishra, A. K. (2001). Trust in physicians and medical institutions: what is it, can it be measured, and does it matter? The Milbank Quarterly, 79(4), 613-639.

Hinkin, C. H., van Gorp, W. G., Satz, P., Marcotte, T., Durvasula, R. S., \& Wood, S. (1996). Actual versus selfreported cognitive dysfunction in HIV-1 infection: Memory-metamemory dissociations. Journal of Clinical Experimental Neuropsychology, 18(3), 431443. 
Kaplan, S. M., Greenfield, S., \& Ware, J. (1989). Assessing the effects of physician-patient interaction on the outcomes of chronic disease. Medical Care, 27(3), $110-127$.

Krawczyńska, A. (2013). Związek pomiędzy zaufaniem do lekarza a postrzeganą jakością usługi medycznej [The relationship between trust in the doctor and the perceived quality of the medical service]. Acta Universitatis Lodziensis Folia Oeconomica, 287, 145-156.

Krivoy, A., Balicer, R. D., Feldman, B., Hoshen, M., Zalsman, G., Weizman, A., \& Shoval, G. (2015). The impact of age and gender on adherence to antidepressants: a 4-year population-based cohort study. Psychopharmacology, 232(18), 3385-3390.

Krot, K., \& Rudawska, I. (2016). The Role of Trust in Doctor-Patient Relationship: Qualitative Evaluation of Online Feedback from Polish Patients. Economics and Sociology, 9(3), 76-88. doi: 10.14254/2071789X.2016/9-3/7

Krueger, K. P., Berger, B. A., \& Felkey, B. (2005). Medication adherence and persistence: A comprehensive review. Advances in Therapy, 22(4), 313-356.

Krueger, K., Botermann, K. L, Schorr, S. G., Griese-Mammen, N., Laufs, U., \& Schulz, M. (2015). Age-related medication adherence in patients with chronic heart failure: A systematic literature review. International Journal of Cardiology, 184(1), 728-735.

Maynard, A., \& Bloor, K. (2003). Trust and performance management in the medical marketplace. Journal of the Royal Society of Medicine, 96(11), 532-539.

Mead, N., \& Bower, P. (2000). Patient-centredness: a conceptual framework and review of the empirical literature. Social Science and Medicine, 51(7), 1087-1110.

Mechanic, D., \& Meyer, S. (2000). Concepts of trust among patients with serious illness. Social Science and Medicine, 51(5), 657-668.

Mercer, S., Watt, G., \& Reilly, D. (2001). Empathy is important for enablement. British Medical Journal, 322(7290), 858-866.

Michetti, P., Peyrin-Biroulet, L., Silverberg, M. S., Louis, E., Weinman, J., Sommer, J., Petersson, J., Pappalardo, B., \& Nurwakagari, P. (2016). Effect of age on beliefs about and adherence to medications in patients with inflammatory bowel disease: result from the ALIGN study. Poster presentation: Clinical: Therapy \& observation, P315.

Murphy, D., Roberts, K., Marelich, W., \& Hoffman, D. (2000). Barriers to antiretroviral adherence among HIV-Infected adults. AIDS Patient Care, 14(1), 47-58.

Ostrop, N., Hallett, K., \& Gill, J. (2000). Long-term patient adherence to antiretroviral therapy. Annals of Pharmacotherapy, 34(6), 703-709.

Reynolds, N. R., Testa, M. A., Marc, L. G., Chesney, M. A., Neidig, J. L., Smith, S. R., Vella, S., \& Robbins, G. K. (2004). Factors influencing medication adherence beliefs and self-efficacy in persons naive to antiretroviral therapy: a multicenter, cross-sectional study. AIDS and Behaviour, 8(2), 141-150.
Roberson, M. H. (1992). The meaning of compliance: patient perspectives. Qualitative Health Research, 2, 7-26.

Roberts, K.J. (2000). Barriers to and facilitators of HIVpositive patients' adherence to antiretroviral treatment regimens. Aids Patient Care STDS, 14, 155-68.

Rost, K. (1989). The influence of patient participation on satisfaction and compliance. The Diabetes Educator Journal, 15(2), 134-138.

Rowe, R., \& Calnan, M. (2006). Trust relations in health care - the new agenda. The European Journal of Public Health, 16(1), 4-6.

Schoenthaler, A., Montague, E., Manwell, L. B., Brown, R., Schwartz, M. D., Linzer, M. (2014). Patient-Physician Racial/Ethnic Concordance and Blood Pressure Control: The Role of Trust and Medication Adherence. Ethnicity \& Health, 19(5), 565-578.

Szymańska, E. (2016). Consumer participation in the health tourism innovation process. Economics and Management, 8(4), 28-38.

Thom, D. H. (2001). Physician behaviors that predict patient trust. The Journal of Family Practice, 50(4), 323-328.

Thom, D. H., Kravitz, R. L., Bell, R. A., Krupat, E., \& Azari, R. (2002). Patient trust in the physician relationship to patient request. Familly Practice, 19(5), 476-483.

Thomas, H., Wroth, M. D., \& Pathman, D. E. (2006). Primary Medication Adherence in a Rural Population: The Role of the Patient-Physician Relationship and Satisfaction with Care. Journal of the American Board Family Medicine, 19(5), 478-486.

Thrasher, A. D., Golin, C. E., \& Zimmer, C. (2008). Discrimination, Distrust, and Racial/Ethnic Disparities in Antiretroviral Therapy Adherence Among a National Sample of HIV-Infected Patients. Journal of Acquired Immune Deficiency Syndromes, 49(1), 84-93.

Trumble, S. C., O'Brien, M. L., O'Brien, M., \& Hartwig, B. (2006). Communication skills training for doctors increases patient satisfaction. Clinical Governance: An International Journal, 11(4), 299-307.

Turner, B., Newschaffer, C., Zhang, D., Cosler, L., \& Hauck, W. (2000). Antiretroviral use and pharmacy-based measurement of adherence in postpartum HIV infected women. Medical Care, 38(9), 911-925.

Van der Schee, E., Groenewegen, P. P., \& Friele, R. D. (2006). Public trust in health care: a performance indicator? Journal of Health Organization and Management, 20(5), 468-476.

Vermeire, E., Hearnshaw, H., Van Royen, P., \& Denekens, J. (2001). Patient adherence to treatment: three decades of research. A comprehensive review. Journal of Clinical Pharmacy and Therapeutics, 26(5), 331-342.

Zineldin, M. (2015). Determinants of patient safety, satisfaction and trust. Clinical Governance: An International Journal, 20(2), 82-90. 